This item was submitted to Loughborough's Research Repository by the author.

Items in Figshare are protected by copyright, with all rights reserved, unless otherwise indicated.

\title{
Quantification of colour stimuli through the calculation of CIE chromaticity coordinates and luminance data for application to in situ colorimetry studies of electrochromic materials
}

\section{PLEASE CITE THE PUBLISHED VERSION}

http://dx.doi.org/10.1016/j.displa.2010.10.001

\section{PUBLISHER}

(C) Elsevier B.V.

\section{VERSION}

AM (Accepted Manuscript)

\section{LICENCE}

CC BY-NC-ND 4.0

\section{REPOSITORY RECORD}

Mortimer, Roger J., and Thomas S. Varley. 2019. "Quantification of Colour Stimuli Through the Calculation of CIE Chromaticity Coordinates and Luminance Data for Application to in Situ Colorimetry Studies of Electrochromic Materials". figshare. https://hdl.handle.net/2134/11421. 
This item was submitted to Loughborough's Institutional Repository (https://dspace.lboro.ac.uk/) by the author and is made available under the following Creative Commons Licence conditions.

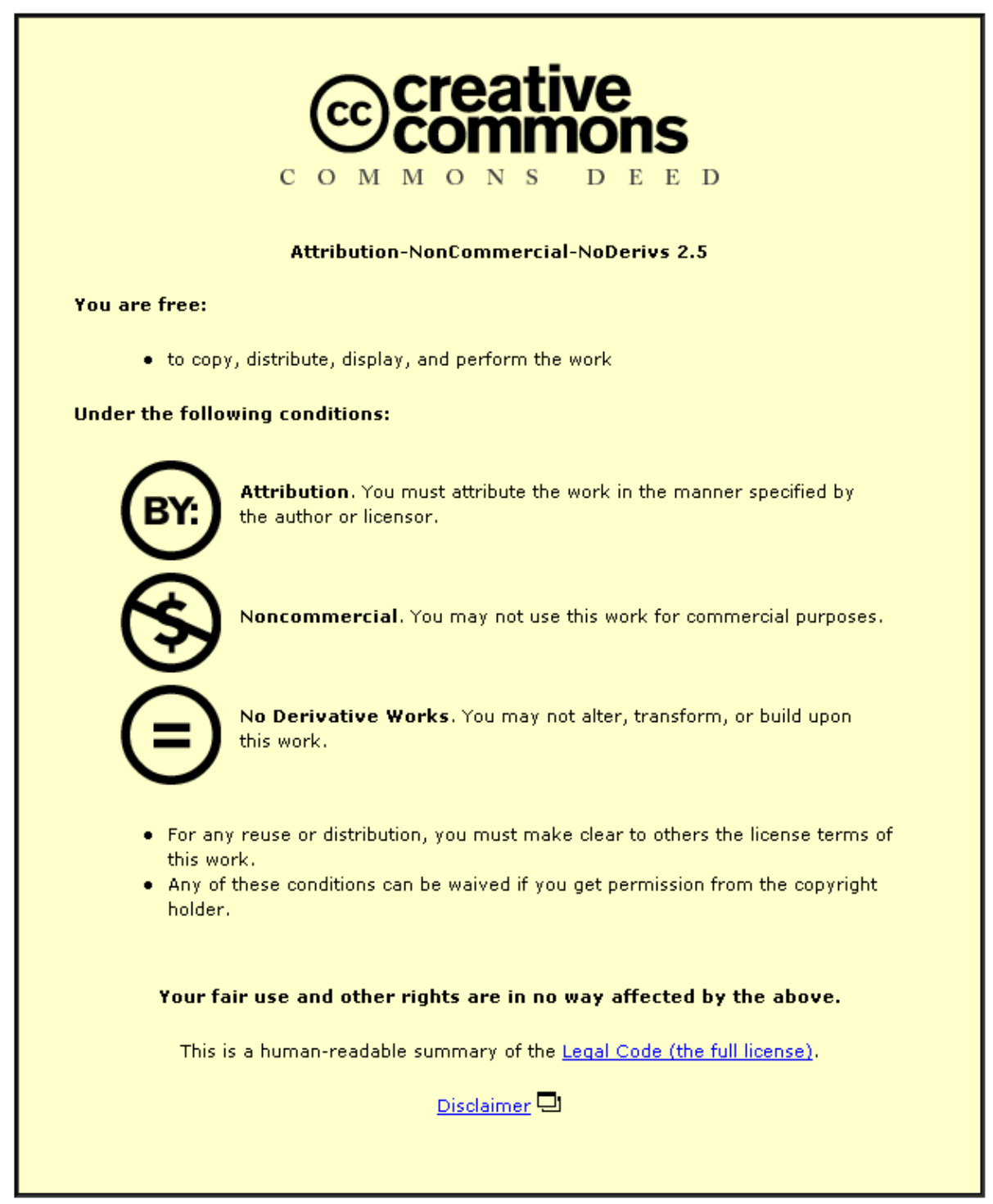

For the full text of this licence, please go to: http://creativecommons.org/licenses/by-nc-nd/2.5/ 


\title{
Quantification of colour stimuli through the calculation
}

\section{of CIE chromaticity coordinates and luminance data for}

\section{application to in situ colorimetry studies of}

\section{electrochromic materials}

\author{
Roger J. Mortimer*, Thomas S. Varley \\ Department of Chemistry, Loughborough University, \\ Loughborough, Leicestershire, LE11 3TU, UK \\ *Corresponding author: Tel. +44 (0)150922 2583 Fax +44 (0)1509 223925 \\ E-mail address: R.J.Mortimer@lboro.ac.uk
}

\begin{abstract}
The development of a Microsoft ${ }^{\circledR}$ Excel $^{\circledR}$ spreadsheet is described, for the accurate calculation of CIE (Commission Internationale de l'Eclairage) 1931 xy chromaticity coordinates and luminance data from visible region absorption spectra recorded in transmission mode. Using firmly established CIE principles, absorbance-wavelength data from visible spectra recorded using a Hewlett Packard 8452A diode array spectrophotometer are taken as input, with chromaticity coordinates being generated as output. The colorimetric transformations described are well known to colour scientists, with the methodology and background now being made accessible to the electrochromic materials community. Colour stimulus measurement example calculation results are firstly presented for aqueous solutions of the dyes, Erythrosin B (red), Acid Green 25 and Remaxol Brilliant Blue R, and then for tracking electrochromic in situ colour stimulus changes in the methyl viologen and $n$-heptyl viologen systems. The quantification of colour during each viologen dication
\end{abstract}


to cation radical reduction process, and each reverse (oxidation) process, showed that subtle changes in both hue and luminance could be detected, with evidence of colour contributions from both the cation radical and the cation radical dimer.

\section{Keywords}

Colorimetry; CIE; Dyes; Electrochromism; Methyl viologen; $n$-Heptyl viologen

\section{Introduction}

\subsection{Background}

In situ visible region spectroelectrochemistry [1-4] has traditionally been used for the characterisation of the colour states of electrochromic materials [5-9]. However, although a visible region spectrum gives an objective measure of colour absorption, it provides little insight into the impact on the human eye of the subjective perception of hue, saturation and relative luminance. Colour scientists have developed several methods of quantifying such concepts [10-12], and commercial colorimeters are available for the quantification of colour stimulus through the measurement of chromaticity coordinates. Colour appearance will depend on many factors including the observer's state of adaption, the absolute luminance levels involved, and the surrounding colours. The specification of the light source is also essential when quantifying colour, as the colour stimulus only exists when a light source is attenuated by transmitting or reflecting materials.

For application in the field of electrochromism, a simple in situ colorimetry method has been developed [13] for the precise control and measurement of colour in electrochromic materials and display devices. A major advantage of this method is that colour stimulus changes may be tracked during colour switching, with the electrochromic material under electrochemical control. Although often used for characterisation in addition to in situ spectroelectrochemistry, colorimetry provides a more precise way to define colour than the measurement of visible region absorbance 
spectra [11]. Rather than record absorption bands, in colorimetry, the human eye's sensitivity to light across the visible region is measured and a numerical description of colour is given. For electrochromic colour changes, unlike with spectroelectrochemistry, colorimetric measurements allow spectral changes over the entire visible region to be plotted as a single colour trajectory on a single graph. In situ colorimetry, using a simple portable colorimeter, has been successfully applied to the colour measurement of numerous electrochromic conjugated polymer films [13-32], the intervalence charge-transfer complex Prussian blue [33], and the $n$-heptyl viologen system [34].

For colour measurements to date, the electrochromic materials community has relied on the use of dedicated tristimulus colorimeters [13-34]. We here describe the development of a userfriendly Microsoft ${ }^{\circledR}$ Excel $^{\circledR}$ spreadsheet, absorbance-wavelength data from visible region spectra being taken as input, with chromaticity coordinates generated as output. For verification, colour measurement example calculation results are presented for standard dye solutions, followed by a study of the electrochromism of two viologen systems. For practitioners without colour science expertise, a brief introduction to the operating principles of a commercial colorimeter is first provided.

\subsection{Operating principle of a commercial colorimeter}

The Minolta CS-100 is “a lightweight, compact meter for taking non-contact measurements of light sources or reflective surfaces” [35] and provides a good example of a commercial colorimeter. Fig. 1 shows a schematic diagram of its internal components. For transmission measurements, light having a known spectral power distribution is directed through a sample and then enters the colorimeter via the protective filter. (Although not studied here, reflected light can also be measured.) The light is chopped and then focused by the objective lens onto the optical fibres, and then split into three channels by the optical fibre cable. The intensity of light in each channel is then modified by a bandpass filter, which imitates the spectral response of the human eye. The shapes of the filter functions are specified by the CIE (Commission Internationale de 
l'Eclairage) $19312^{\circ}$ Standard Observer, where the $2^{\circ}$ refers to the size (in degrees of visual angle) of the split-colour target used in the experiments that were used to derive the colour matching functions, as labelled (a) $\bar{x}$, (b) $\bar{y}$ and (c) $\bar{z}$ in Fig. 2 [12]. The human eye's cones' spectral responses are known as $l, m, s$ (long, medium and short) and are linear combinations of the colour matching functions. Each channel of filtered light is then integrated by a silicon photocell to give a single value current output. The currents are then converted to proportional voltages by analogueto-digital converters. Finally, the data are transformed by the microcomputer to values of luminance $Y$, and chromaticity coordinates $x$ and $y$ [35]. Roughly speaking $x$ measures the red-toblue ratio of the signal, and $y$ measures the green-to-blue ratio.

It is clear from the above discussion that commercial colorimeters implement the measurement of tristimulus values in hardware. The same result can be obtained in software, the output of a visible region spectrophotometer being used as input into a suitable computer spreadsheet. In the present work, such a spreadsheet based on Microsoft ${ }^{\circledR}$ Excel $^{\circledR}$ has been developed and applied to colour measurements for commercially available dyes and two viologen electrochromic materials. In situ colorimetry of the methyl viologen system is presented for the first time, with study of the $n$-heptyl viologen system allowing comparison of data with that we earlier obtained using a commercial colorimeter [34].

\section{Theory}

The calculation method and theory below, is a review of firmly established CIE principles, and is presented for the benefit of those electrochromic materials scientists who may not have a background in colour science. Emphasis is given to the data input and processing required of the computer spreadsheet.

In order to generate chromaticity coordinates from the output of a visible region spectrophotometer, a computer spreadsheet must contain numerical data describing the chromatic responses of the three types of cone in the human eye. These colour matching functions can be 
thought of as the software equivalents of the detectors that yield the CIE tristimulus values $X, Y$, and Z. The full set of numerical values of these functions constitutes the CIE Standard Observer.

The mathematical relationships between the tristimulus values $X, Y$ and $Z$ and the colour matching functions $\bar{x}, \bar{y}$ and $\bar{z}$ (for a CIE $19312^{\circ}$ Standard Observer) are given by equations (1) to (3).

$$
\begin{aligned}
& X=\int_{300}^{780} I(\lambda) \bar{x}(\lambda) \mathrm{d} \lambda \\
& Y=\int_{300}^{780} I(\lambda) \bar{y}(\lambda) \mathrm{d} \lambda \\
& Z=\int_{300}^{780} I(\lambda) \bar{Z}(\lambda) \mathrm{d} \lambda
\end{aligned}
$$

$I(\lambda)$ is the normalised spectral power distribution, and $\lambda$ is the wavelength.

The CIE recommends (12) that the integration can be carried out by discrete numerical summation, and such computation is straightforward when using a computer spreadsheet:

$$
\begin{aligned}
& X=\sum_{\lambda} I(\lambda) \bar{x}(\lambda) \Delta \lambda \\
& Y=\sum_{\lambda} I(\lambda) \bar{y}(\lambda) \Delta \lambda \\
& Z=\sum_{\lambda} I(\lambda) \bar{Z}(\lambda) \Delta \lambda
\end{aligned}
$$

The normalised spectral power distribution of the sample $I(\lambda)$ is related to the un-normalised spectral power distribution of the sample $\varnothing(\lambda)$ by the equation

$$
I(\lambda)=k \phi(\lambda)
$$

where the normalising constant $k$ is

$$
k=1 / \sum_{\lambda} \phi(\lambda) \Delta \lambda
$$

(Note however, it is not essential to normalise the spectrum at this stage through use of equations (7) and (8). Because the computations are linear, the $X Y Z$ values could be normalised later.) 
The definition of the spectral power distribution $\varnothing(\lambda)$ depends upon whether the analysed light is viewed by reflection or transmission. If viewed by reflection then

$$
\phi_{\mathrm{R}}(\lambda)=\rho(\lambda) S(\lambda)
$$

and if viewed by transmission then

$$
\phi_{\mathrm{T}}(\lambda)=\tau(\lambda) S(\lambda)
$$

In the above equations, $\rho(\lambda)$ is the ideal spectral reflectance, $\tau(\lambda)$ is the ideal spectral transmittance, and $S(\lambda)$ is the spectral power distribution of the light source, which must be specified If $S(\lambda)=1$, the light source is also ideal i.e., the light source has the same output at all wavelengths. Although chromaticity coordinates can be calculated from reflectance measurements, the dyes in solution and electrochromic materials investigated here are measured in transmission, therefore, all following calculations will involve and refer to transmission (Equation (10)).

One can take an experimental transmittance (or reflectance) measurement, and with knowledge of the spectral power distribution of the light source, compute the tristimulus values $X, Y$ and $Z$ of the colour. In order for colour representation in 2-D space, the tristimulus values can be converted to chromaticity coordinates $(x, y, z)$ by the following equations

$$
\begin{gathered}
x=\frac{X}{X+Y+Z} \\
y=\frac{Y}{X+Y+Z} \\
Z=\frac{Z}{X+Y+Z}=1-x-y
\end{gathered}
$$

Finally, the luminance factor $Y_{\mathrm{L}}$ is defined as the ratio of the luminance of the transmitter $(Y)$ to that of a perfect transmitter $\left(Y_{0}\right)$ under the same conditions.

$$
Y_{L}=\frac{Y}{Y_{0}}
$$


A flow chart may be used to describe the processing of data through a particular computer program/spreadsheet, showing the exact sequence of operations performed by that program in order to process the data. In the present work the spreadsheet flow chart in Fig. 3 corresponds to the logic of the Microsoft ${ }^{\circledR}$ Excel $^{\circledR}$ spreadsheet.

\section{Experimental}

Electrochemical experiments were performed used an ECO Chemie Autolab PGSTAT 20 potentiostat, with visible region spectra in transmission mode recorded using a Hewlett Packard 8452A diode array spectrophotometer, with a $1 \mathrm{~cm}$ pathlength cuvette. In the computation of CIE 1931 chromaticity coordinates, the spectral power distribution of the D55 light source is used for all cases except the additional data shown in Fig. 8, where the effect of using other light sources is demonstrated. All chemicals (Sigma-Aldrich) were used without further purification. Working electrodes were either Bio Analytical Systems Inc. glassy carbon disks $\left(A=0.0707 \mathrm{~cm}^{2}\right)$, or Delta Technologies Ltd. tin-doped indium oxide (ITO) on Corning ${ }^{\circledR} 1737$ aluminosilicate glass (CB50IN-CUV, $\left.A=3.5 \mathrm{~cm}^{2}(7 \times 50 \times 0.7 \mathrm{~mm}), R_{S}=5-15 \Omega \square^{-1}\right)$. The counter electrode was platinum gauze and the reference electrode was $\mathrm{Ag} / \mathrm{AgCl}\left(3.0 \mathrm{~mol} \mathrm{dm}^{-3} \mathrm{NaCl}\right)$.

\section{Results and discussion}

\subsection{Measurements on standard dye solutions}

\subsubsection{Assessment of reproducibility}

To assess the reproducibility of the quantified colour stimulus through the calculation of chromaticity coordinates, five samples each of Erythrosin B (a red dye), Acid Green 25, and Remazol Brilliant Blue $\mathrm{R}$ were dissolved in water $\left(1 \mathrm{mmol} \mathrm{dm}^{-3}\right)$ and tested independently. The dye structures are shown in Fig. 4. The calculated chromaticity coordinates, shown in Tables 1-3, 
demonstrate that the data are reproducible to three significant figures. Repeated spectral measurements were likewise reproducible.

\subsubsection{Effects of dilution}

A series of experiments was next performed to determine the effects of dilution on both the visible region spectra and chromaticity coordinates of the dyes. For the results shown in Figs. 5-7, in each case the visible region absorption spectrum is shown on the left and the location of the dye on the CIE 1931 colour space chromaticity diagram is shown on the right. As expected, the colour trajectory is from near-monochromatic colour at high concentrations to near colourless at low concentrations. The absorbance spectra for the $1.0 \mathrm{mmol} \mathrm{dm}{ }^{-3}$ solutions exceed the limits of the spectrophotometer's accurate detection ability. However, this does not affect the chromaticity coordinate data as absorbance measurements are converted to transmittance before calculation. Increasing values in absorbance are decreasing in transmittance, which asymptote towards zero.

\subsubsection{Effect of different light sources}

The effect of a change in the light source on the quantification of the colour stimulus through the measurement of chromaticity coordinates can be demonstrated by choice of the appropriate spectral power distribution data. This is shown for $1 \mathrm{mmol} \mathrm{dm}^{-3}$ Erythrosin B in Fig. 8. (The cross hair shows the (achromatic) white spot, or point of equal energy, where $x=y=z=1 / 3$, which does not change. Note, however, the chromaticity coordinates for the colour white (transparent) do depend on the illuminant source and will vary [36]). Due to the near-coincidence of the data, the plot is shown enlarged on the right hand side, which clearly shows that the dye solution will exhibit slight differences in colour stimulus under different light sources. The effect would be greatly magnified in chromaticity if the dye absorbs less, the colour being closer to white.

\subsection{Quantifying electrochromic colour changes}

Calculations using the spreadsheet were next used to quantify the colour changes that occur during redox cycling of electrochromic materials, with methyl viologen dichloride (MV), and $n$ - 
heptyl viologen dibromide (HV), as test compounds. Methyl viologen is a well-known type I electrochromic material, soluble in aqueous solution in both redox states $\left(\mathrm{MV}^{2+}\right.$ dication and $\mathrm{MV}^{+\bullet}$ cation radical). By contrast, $n$-heptyl viologen is a well-known type II electrochromic material, the soluble $\mathrm{HV}^{2+}$ dication being deposited as the $\mathrm{HV}^{+\bullet}$ cation radical salt, following reduction.

Absorbance spectra for the methyl viologen system at various different electrode potentials are shown in Fig. 9. The UV-visible region absorbance increases as the methyl viologen dication is reduced to the cation radical. At the relatively fast scan rates $\left(100 \mathrm{mV} \mathrm{s}^{-1}\right)$ used here, re-oxidation, with absorbance decrease, then takes place before dications can diffuse away from the electrode surface. The voltammogram of this process is shown in Fig. 10, together with an integration of the voltammogram and the calculated relative luminance. The cation radical, which is blue, is known to dimerise to a red form, the generated dark purple colour, a mixture of the two forms, causing the luminance to sharply decrease [37]. The hysteresis is related to the solubility of both redox species. Colour trajectories of the electrochromic reactions in CIE 1931 colour space are shown in Fig. 11, where the parameters $x$ and $y$ represent the red-to-blue ratio, and the green-to-blue ratio, respectively. Although the parameters $x$ and $y$ are nearly state functions of each other (i.e., no hysteresis), a small amount of hysteresis is in fact visible when the scales are enlarged. This suggests that more than one colour generating process is taking place during the cyclic voltammetry and it seems likely that this relates to the cation radical dimerisation process. Supporting evidence in favour of this hypothesis is provided by Fig. 9, which shows that, during the reduction process, the sharp peak at circa $400 \mathrm{~nm}$ due to the monomer is smaller than the broad peak at circa $360 \mathrm{~nm}$ due to the dimer, whereas during the oxidation process the situation is reversed [37].

Absorbance spectra for the $n$-heptyl viologen system at various different electrode potentials are shown in Fig. 12. The UV-visible region absorbance increases as the $n$-heptyl viologen is reduced to the cation radical salt, and then decreases as the cation radical is reoxidised. The voltammogram of this process is shown in Fig. 13, together with an integration of the voltammogram and the calculated relative luminance. As would be expected, the relative 
luminance decreases sharply as the purple cation radical salt is formed. Compared with the methyl viologen system, the diminished hysteresis is related to the fact that the cation radical of $n$-heptyl viologen is insoluble in aqueous solution. Once again it was possible to generate colour trajectories of the electrochromic reactions in the CIE 1931 colour space, as shown in Fig. 14. As seen in the case of methyl viologen, a small amount of hysteresis is observed between the parameters $x$ and $y$ during cyclic voltammetry, possibly related to dimerisation reactions of the cation radical. The trends in the luminance and chromaticity coordinates changes are verified as being comparable to our earlier in situ colorimetric studies [34] of the $n$-heptyl viologen system using the Minolta CS100 colorimeter, with the slight differences being attributed to the illuminant source used and the method of electrochemical potential control. Earlier, a D50 standard illuminant constant temperature daylight simulating light source was used [34], whereas all the data displayed currently were calculated using the spectral power distribution of a D55 illuminant source. Furthermore, rather than use of cyclic voltammetry, measurements had been made at a sequence of applied potential steps, with chromaticity coordinates being measured after the current had decayed to background levels, following the application of each applied potential [34]. Further verification of the accuracy of the spreadsheet calculations was provided by use of spectral data recorded for our earlier Prussian blue colorimetry research [33], where for the same sample, we had simultaneously recorded spectra with a scanning spectrophotometer and taken measurements with a Minolta CS100 colorimeter. Chromaticity coordinates now calculated from the spectral data (from figure 2 of [33]) are in good agreement with those first measured using the colorimeter.

\section{Conclusion}

The quantification of colour during electrochromic reactions is a very desirable goal. The present work has succeeded in developing, and implementing, a simple spreadsheet for the calculation of precise values of luminance and chromaticity coordinates from real-time visible region absorption spectra. The method is based on the integration of experimental spectral power 
distributions derived from visible region spectra over the CIE 1931 colour-matching functions. The electrochromic materials community will be able to adopt this approach for colour measurement, without the need for dedicated tristimulus colorimeters. Proof-of-concept experiments, using the methyl viologen and $n$-heptyl viologen systems showed that subtle changes in both hue and luminance could be detected in an informative and intuitive way, with colour trajectories providing clear indications of multiple coloured species in even the simplest systems.

\section{References}

[1] W.R. Heineman, W.B. Jensen, Spectroelectrochemistry using transparent electrodes - an anecdotal history of the early years, in: J.T. Stock, M.V. Orna (Eds.), Electrochemistry, Past and Present, American Chemical Society, Washington, DC, 1989, ACS Symposium Series, Volume 390, pp. 442-457.

[2] J. Niu, S. Dong, Transmission spectroelectrochemistry, Rev. Anal. Chem. 15 (1996) 1-171.

[3] R.J. Mortimer, Electronic Spectroscopy: Spectroelectrochemistry, Applications, in: J.C. Lindon, G.E. Tranter, J.L. Holmes (Eds.), Encyclopedia of Spectroscopy and Spectrometry, Academic Press, London, 2000, Volume 3, pp. 2161-2174.

[4] R.J. Mortimer, Electronic Spectroscopy: Spectroelectrochemistry, Methods and Instrumentation, in: J.C. Lindon, G.E. Tranter, J.L. Holmes (Eds.), Encyclopedia of Spectroscopy and Spectrometry, Academic Press, London, 2000, Volume 3, pp. 2174-2181.

[5] R.J. Mortimer, D.R. Rosseinsky, Iron hexacyanoferrate films: Spectroelectrochemical distinction and electrodeposition sequence of ‘soluble’ $\left(\mathrm{K}^{+}\right.$-containing) and ‘insoluble’ $\left(\mathrm{K}^{+}\right.$free) Prussian blue and composition changes in polyelectrochromic switching, J. Chem. Soc. Dalton Trans. (1984) 2059-2061.

[6] R.J. Mortimer, Spectroelectrochemistry of electrochromic poly(o-toluidine) and poly $(m-$ toluidine) films, J. Mater. Chem. 5 (1995) 969-973. 
[7] R.J. Mortimer, J.L. Dillingham, Electrochromic 1,1'-dialkyl-4,4'-bipyridilium-incorporated Nafion ${ }^{\circledR}$ electrodes, J. Electrochem. Soc. 144 (1997) 1549-1553.

[8] A. Kumar, D.M. Welsh, M.C. Morvant, F. Piroux, K.A Abboud, J.R. Reynolds, Conducting poly(3,4-alkylenedioxythiophene) derivatives as fast electrochromics with high-contrast ratios, Chem. Mater. 10 (1998) 896-902.

[9] X. Hu, Q. Wang, P. He, Y. Fang, Spectroelectrochemistry study on the electrochemical reduction of ethidium bromide, Anal. Sci. 18 (2002) 645-650.

[10] R.G. Kuehni, Color: An Introduction to Practice and Principles, second ed., John Wiley and Sons, Inc., Hoboken, New Jersey, 2005.

[11] G. Wyszecki, W.S. Stiles, Color Science: Concepts and Methods, Quantitative Data and Formulae, second ed., John Wiley and Sons, New York, 1982.

[12] CIE Technical Report: Colorimetry, third ed.; Commission Internationale De l’Eclairage: Vienna, Austria, 2004.

[13] B.C. Thompson, P. Schottland, K.W. Zong, J.R. Reynolds, In situ colorimetric analysis of electrochromic polymers and devices, Chem. Mater. 12 (2000) 1563-1571.

[14] B.C. Thompson, P. Schottland, G. Sönmez, J.R. Reynolds, In situ colorimetric analysis of electrochromic polymer films and devices, Synth. Met. 119 (2001) 333-334.

[15] I. Schwendeman, R. Hickman, G. Sönmez, P. Schottland, K. Zong, D.M. Welsh, J.R. Reynolds, Enhanced contrast dual polymer electrochromic devices, Chem. Mater. 14 (2002) 3118-3122.

[16] G. Sönmez, I. Schwendeman, P. Schottland, K. Zong, J.R. Reynolds, N-Substituted poly(3,4-propylenedioxypyrrole)s: High gap and low redox potential switching electroactive and electrochromic polymers, Macromolecules 36 (2003) 639-647.

[17] A. Cirpan, A.A. Argun, C.R.G. Grenier, B.D. Reeves, J.R. Reynolds, Electrochromic devices based on soluble and processable dioxythiophene polymers, J. Mater. Chem. 13 (2003) 2422-2428. 
[18] B.D. Reeves, C.R.G. Grenier, A.A. Argun, A. Cirpan, T.D. McCarley, J.R. Reynolds, Spray coatable electrochromic dioxythiophene polymers with high coloration efficiencies, Macromolecules 37 (2004) 7559-7569.

[19] G. Sönmez, H. Meng, F Wudl, Organic polymeric electrochromic devices: Polychromism with very high coloration efficiency, Chem. Mater. 16 (2004) 574-580.

[20] G. Sönmez, C.K.F. Shen, Y. Rubin, F. Wudl, A red, green, and blue (RGB) polymeric electrochromic device (PECD): The dawning of the PECD era, Angew. Chem., Int. Ed. 43 (2004) 1498-1502.

[21] C.A. Thomas, K. Zong, K.A. Abboud, P.J. Steel, J.R. Reynolds, Donor-mediated band gap reduction in a homologous series of conjugated polymers, J. Am. Chem. Soc. 126 (2004) 16440-16450.

[22] L. Sacan, A. Cirpan, P. Camurlu, L. Toppare, Conducting polymers of succinic acid bis-(2thiophen-3-yl-ethyl)ester and their electrochromic properties, Synth. Met. 156 (2006) 190195.

[23] S.C. Nunes, V. de Zea Bermudez, M.M. Silva, M.J. Smith, D. Ostrovskii, R.A. Sá Ferreira, L.D. Carlos, J. Rocha, A. Gonçalves, E. Fortunato, Sol-gel-derived potassium-based diureasils for ‘smart windows’, J. Mater. Chem. 17 (2007) 4239-4248.

[24] E. Unur, J-H. Jung, R.J. Mortimer, J.R. Reynolds, Dual-polymer electrochromic film characterization using bipotentiostatic control, Chem. Mater. 20 (2008) 2328-2334.

[25] P.M. Beaujuge, S. Ellinger, J.R. Reynolds, Spray processable green to highly transmissive electrochromics via chemically polymerizable donor-acceptor heterocyclic pentamers, Adv. Mater. 20 (2008) 2772-2776.

[26] P.M. Beaujuge, S. Ellinger, J.R. Reynolds, The donor-acceptor approach allows a black-totransmissive switching polymeric electrochrome, Nat. Mater. 7 (2008) 795-799. 
[27] S. Tarkuc, Y. Arslan Udum, L. Toppare, Tuning of the neutral state color of the $\pi$ conjugated donor-acceptor-donor type polymer from blue to green via changing the donor state of the polymer, Polymer 50 (2009) 3458-3464.

[28] H. Seol, H. Jeong, S. Jeon, Optoelectrochemical properties of copolymer of terthiophene with 3,4-ethlenedioxypyrrole, J. Electroanal. Chem. 636 (2009) 107-112.

[29] R.J. Mortimer, K.R. Graham, C.R.G. Grenier, J.R. Reynolds, Influence of the film thickness and morphology on the colorimetric properties of spray-coated electrochromic disubstituted 3,4-propylenedioxythiophene polymers, ACS Appl. Mater. Interfaces 1 (2009) 2269-2276.

[30] S.V. Vasilyeva, E. Unur, R.M. Walczak, E.P. Donoghue, A.G. Rinzler, J.R. Reynolds, Color purity in polymer electrochromic window devices on indium-tin oxide and single-walled carbon nanotube electrodes, ACS Appl. Mater. Interfaces 1 (2009) 2288-2297.

[31] E. Unur, P.M. Beaujuge, S. Ellinger, J-H. Jung, J.R. Reynolds, Black to transmissive switching in a pseudo three-electrode electrochromic device, Chem. Mater. 21 (2009) 51455153.

[32] C.M. Amb, P.M. Beaujuge, J.R. Reynolds, Spray-processable blue-to-highly transmissive switching polymer electrochromes via the donor-acceptor approach, Adv. Mater. 22 (2010) 724-728.

[33] R.J. Mortimer, J.R. Reynolds, In situ colorimetric and composite coloration efficiency measurements for electrochromic Prussian blue, J. Mater. Chem. 15 (2005) 2226-2233.

[34] R.J. Mortimer, J.R. Reynolds, An in situ colorimetric measurement study of electrochromism in the di-n-heptyl viologen system, Displays 29 (2008) 424-431.

[35] Chroma-Meter CS-100. Instruction Manual (http://www.konicaminolta.com/sensingusa/support/manuals) 1-42. (accessed on 30 March 2010).

[36] M. Shaw, M. Fairchild, Evaluating the 1931 CIE color-matching functions, Color Res. Appl. 27 (2002) 316-329. 
[37] P.M.S. Monk, The Viologens: Physicochemical Properties, Synthesis and Applications of the Salts of 4,4'-Bipyridine. John Wiley and Sons, Chichester, 1998, pp. 115-131.

\section{Acknowledgements}

We thank Loughborough University and the departmental EPSRC Doctoral Training Grant for provision of a research studentship to TSV, and Professor Stephen Fletcher and Dr Sandie E Dann for their encouragement and helpful discussions. The detailed constructive comments of a reviewer are gratefully acknowledged. 


\section{Figure captions}

Fig. 1

Schematic diagram of the Minolta XS-100 colorimeter taken from the Chroma-Meter CS-100 Instruction Manual.

Fig. 2

CIE $19312^{\circ}$ standard observer colour matching functions, where (a) is $\bar{x}$, (b) is $\bar{y}$ and (c) is $\bar{z}$. The data used to create this graph was taken from CIE Technical Report: Colorimetry, third ed.; Commission Internationale De l’Eclairage: Vienna, Austria, 2004.

Fig. 3

A flow chart showing the exact sequence of operations performed in the Microsoft ${ }^{\circledR}$ Excel $^{\circledR}$ spreadsheet to transform visible region spectral absorbance data into chromaticity coordinates.

Fig. 4

Chemical structures of: (1) Erythrosin B; (2) Acid Green 25; and (3) Remazol Brilliant Blue R.

Fig. 5

UV-visible region spectra (1) and CIE 1931 chromaticity coordinates (2), for the red dye Erythrosin

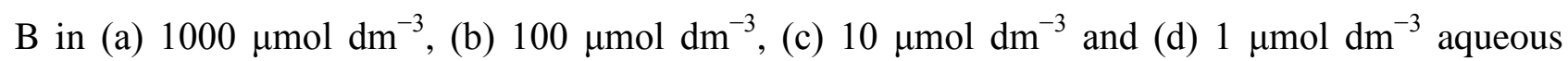
solutions. For here and all reported spectra, $A$, the absorbance is equivalent to optical density and is defined as $\log _{10}\left(I_{0} / I\right)$, where $I_{0}$ is the incident and $I$ the transmitted light intensity.

Fig. 6

UV-visible region spectra (1) and CIE 1931 chromaticity coordinates (2), for Acid Green 25 in (a) $1000 \mu \mathrm{mol} \mathrm{dm}{ }^{-3}$, (b) $100 \mu \mathrm{mol} \mathrm{dm}{ }^{-3}$, (c) $10 \mu \mathrm{mol} \mathrm{dm}{ }^{-3}$ and (d) $1 \mu \mathrm{mol} \mathrm{dm}{ }^{-3}$ (not viewable on this scale) aqueous solutions.

Fig. 7

UV-visible spectra (1) and CIE 1931 chromaticity coordinates (2), for Remazol Brilliant Blue R in (a) $1000 \mu \mathrm{mol} \mathrm{dm}{ }^{-3}$, (b) $100 \mu \mathrm{mol} \mathrm{dm}{ }^{-3}$, (c) $10 \mu \mathrm{mol} \mathrm{dm}{ }^{-3}$ and (d) $1 \mu \mathrm{mol} \mathrm{dm}{ }^{-3}$ (not viewable on this scale) aqueous solutions. 
Fig. 8

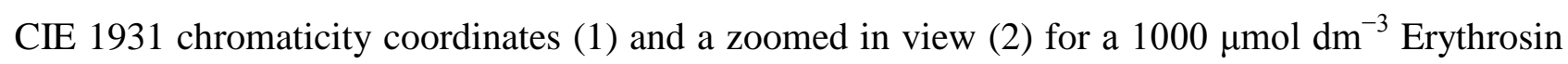
B aqueous solution. The different spectral power distributions used were for the light sources (a) standard illuminant A, (b) standard illuminant D65, (c) illuminant C, (d) illuminant D50, (e) illuminant D55, (f) fluorescent lamp 1 (F1) and (g) high pressure discharge lamps (HP1).

Fig. 9

UV-visible region absorbance spectra, recorded every $1 \mathrm{~s}$, at an ITO-glass working electrode in a 2 mmol $\mathrm{dm}^{-3}$ methyl viologen dichloride $/ 1.0 \mathrm{~mol} \mathrm{dm}{ }^{-3}$ potassium chloride aqueous solution. In tandem, the electrode potential was cycled from $0.0 \mathrm{~V} \rightarrow-0.8 \mathrm{~V} \rightarrow 0.0 \mathrm{~V}$, at $100 \mathrm{mV} \mathrm{s}$. The arrows indicate the direction of change in absorbance, starting at $0.0 \mathrm{~V}$.

Fig. 10

(1) Cyclic voltammogram, (2) integrated voltammogram (with the contribution of $\mathrm{O}_{2}$ omitted) and (3) calculated relative luminance vs. potential, for reduction/oxidation of $2 \mathrm{mmol} \mathrm{dm}^{-3}$ methyl viologen dichloride in a $1.0 \mathrm{~mol} \mathrm{dm}{ }^{-3}$ potassium chloride aqueous solution. A glassy carbon working electrode was used when recording the voltammogram. Luminance data were calculated from data using an ITO-glass working electrode. The corresponding numerical data are shown in Table 4. The arrows indicate the direction of the potential scan, starting from $0.0 \mathrm{~V}$.

Fig. 11

Colour trajectories of electrochromic reactions in the CIE 1931 colour space. (1) Reduction and reoxidation of methyl viologen dication. (2) Magnified view of the same data. Note the slight hysteresis possibly related to variations in the monomer/dimer ratio of the methyl viologen radical cation. The corresponding numerical data are shown in Table 4.

Fig. 12

UV-visible region absorbance spectra, recorded every $1 \mathrm{~s}$, at an ITO-glass working electrode in a 2 mmol dm ${ }^{-3} n$-heptyl viologen dibromide $/ 1.0 \mathrm{~mol} \mathrm{dm}^{-3}$ potassium bromide aqueous solution. In 
tandem, the electrode potential was cycled from $0.0 \mathrm{~V} \rightarrow-0.7 \mathrm{~V} \rightarrow 0.0 \mathrm{~V}$, at $100 \mathrm{mV} \mathrm{s}$. The arrows indicate the direction of change in absorbance, starting at $0.0 \mathrm{~V}$.

Fig. 13

(1) Cyclic voltammogram, (2) integrated voltammogram (with the contribution of $\mathrm{O}_{2}$ omitted) and

(3) calculated relative luminance vs. potential, for reduction/oxidation of $2 \mathrm{mmol} \mathrm{dm}^{-3} n$-heptyl viologen dibromide in an aqueous solution containing potassium bromide $\left(1.0 \mathrm{~mol} \mathrm{dm}{ }^{-3}\right)$. A glassy carbon working electrode was used when recording the voltammogram. Luminance data were calculated from data using an ITO-glass working electrode. The corresponding numerical data are shown in Table 5. The arrows indicate the direction of the potential scan, starting from $0.0 \mathrm{~V}$.

Fig. 14

Colour trajectories of electrochromic reactions in the CIE 1931 colour space. (1) Reduction and reoxidation of $n$-heptyl viologen dication. (2) Magnified view of the same data. Note the small hysteresis possibly related to variations in the monomer/dimer ratio of the $n$-heptyl viologen radical cation. The corresponding numerical data are shown in Table 5. 
Fig.1

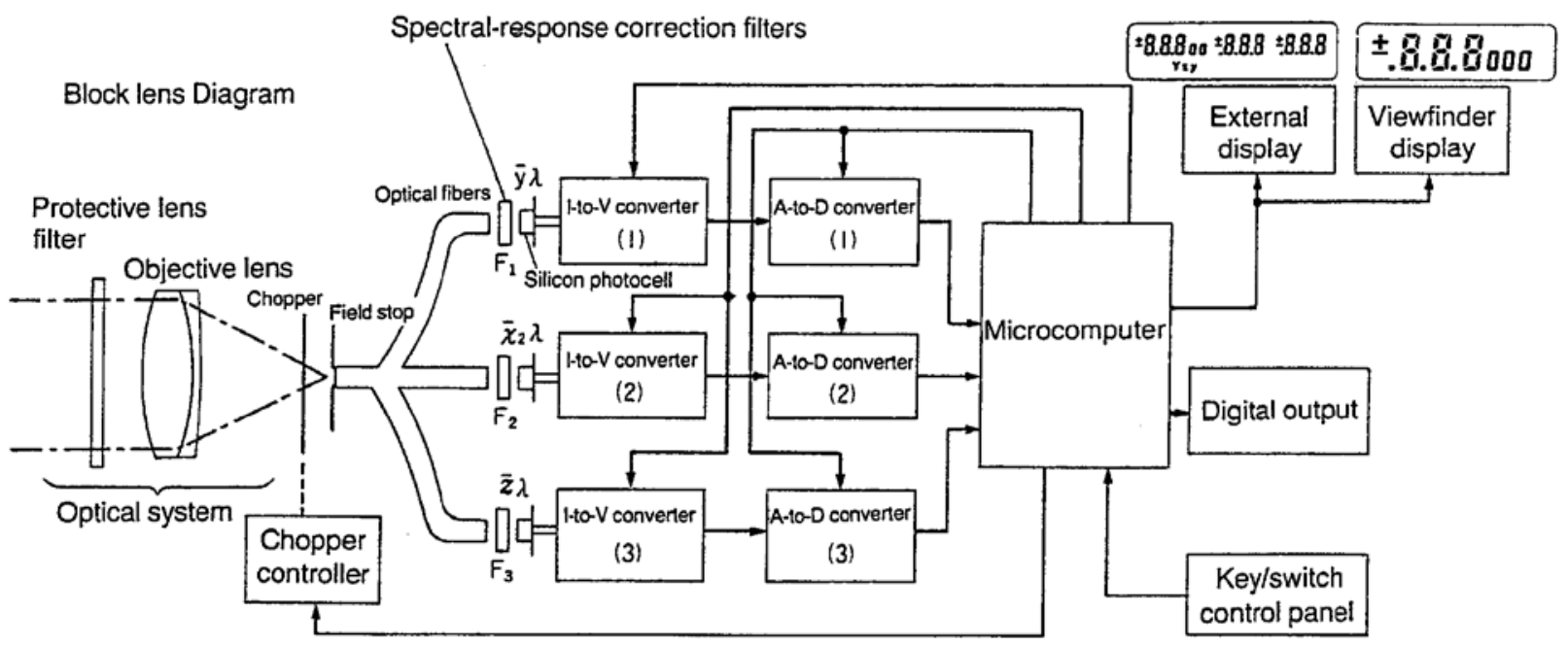


Fig. 2

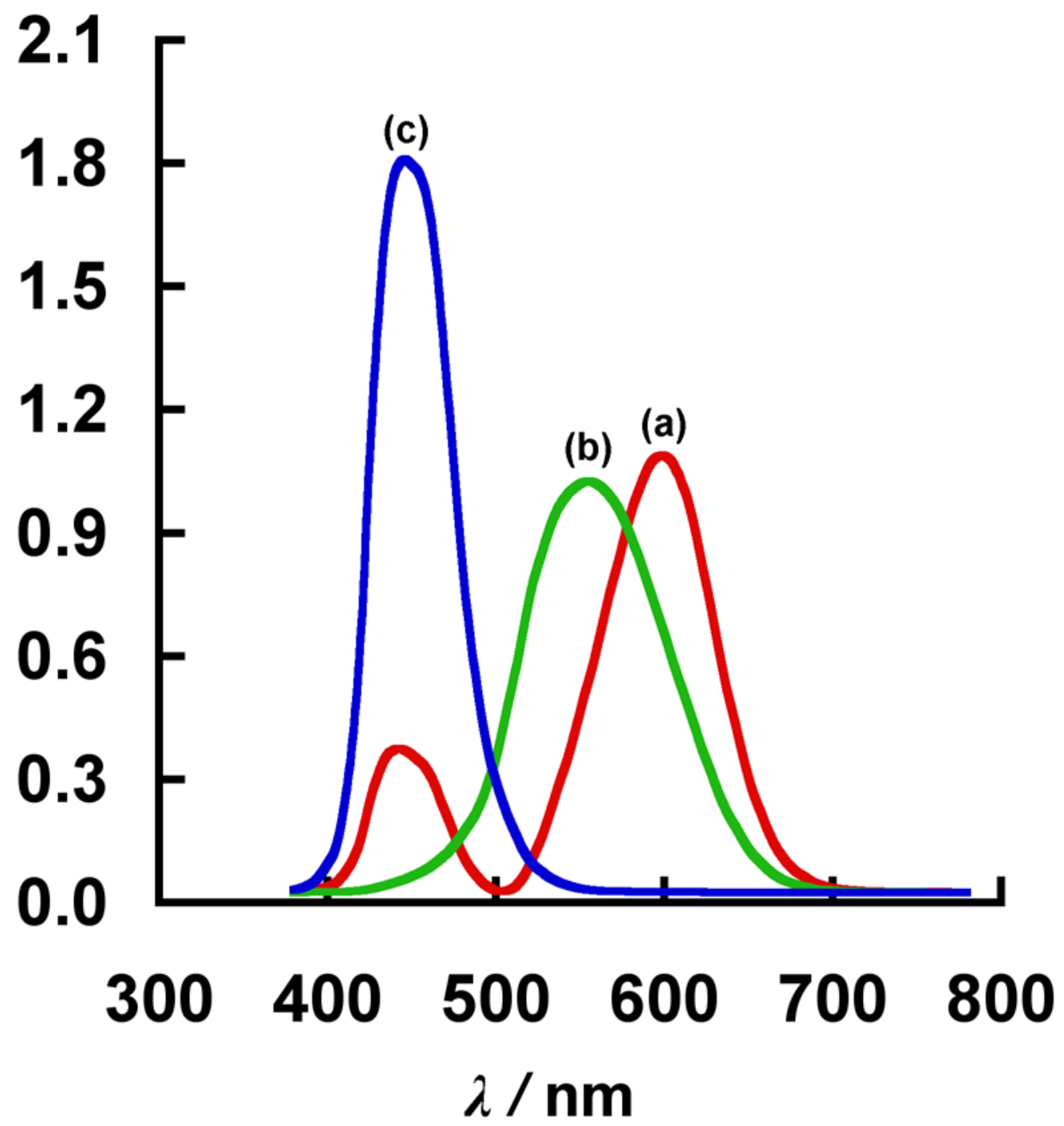


Fig. 3

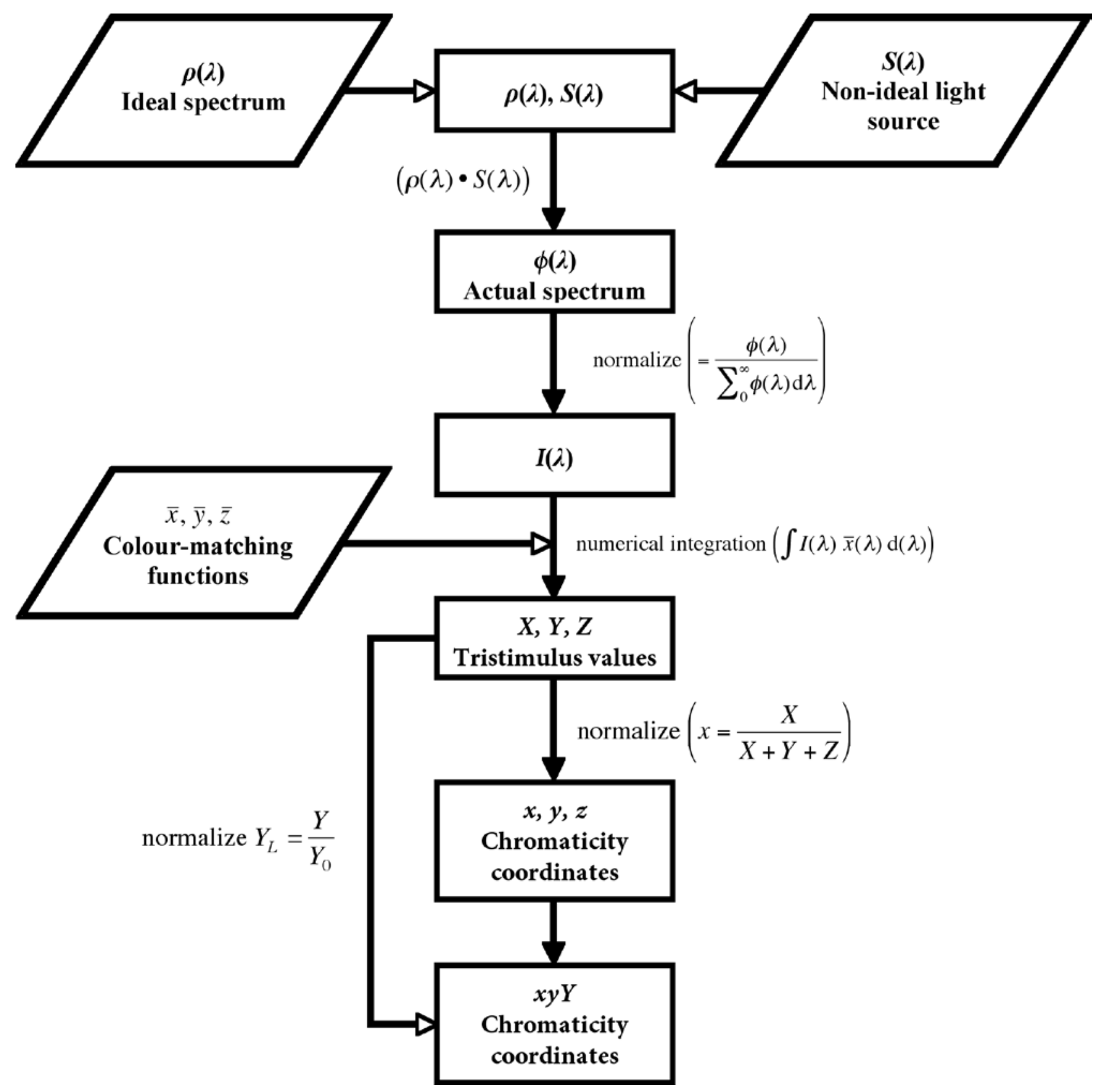


Fig. 4

(1)

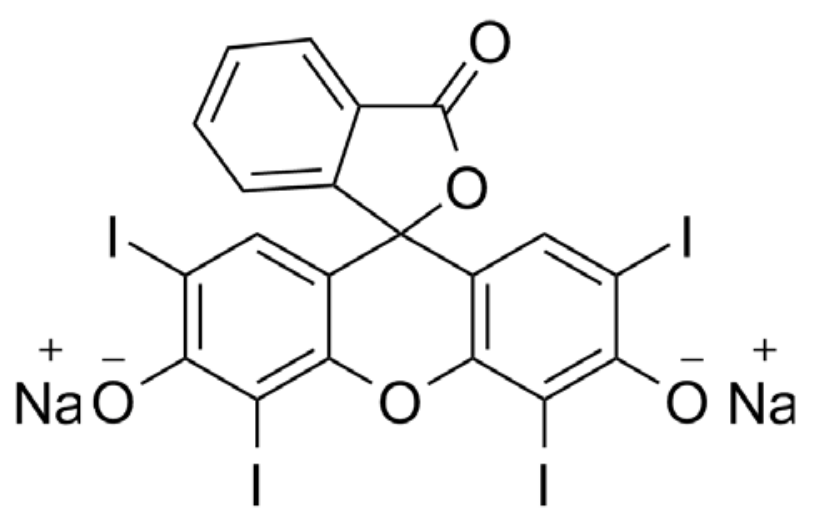

(2)

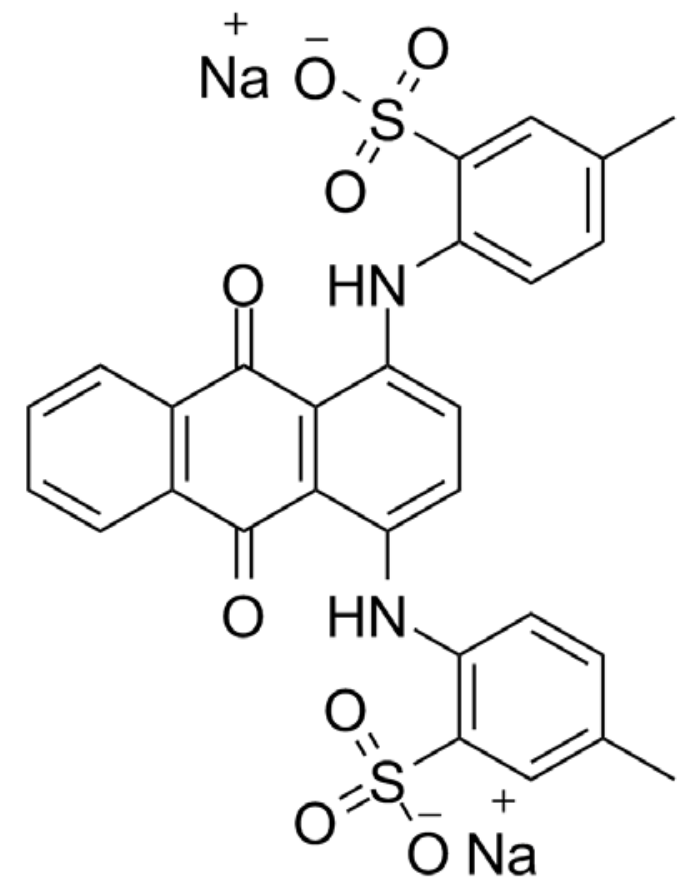

(3)<smiles>Nc1c(S(=O)(=O)[O-])cc(Nc2cccc(S(=O)(=O)CCOS(=O)(=O)[O-])c2)c2c1C(=O)c1ccccc1C2=O</smiles> 
Fig. 5
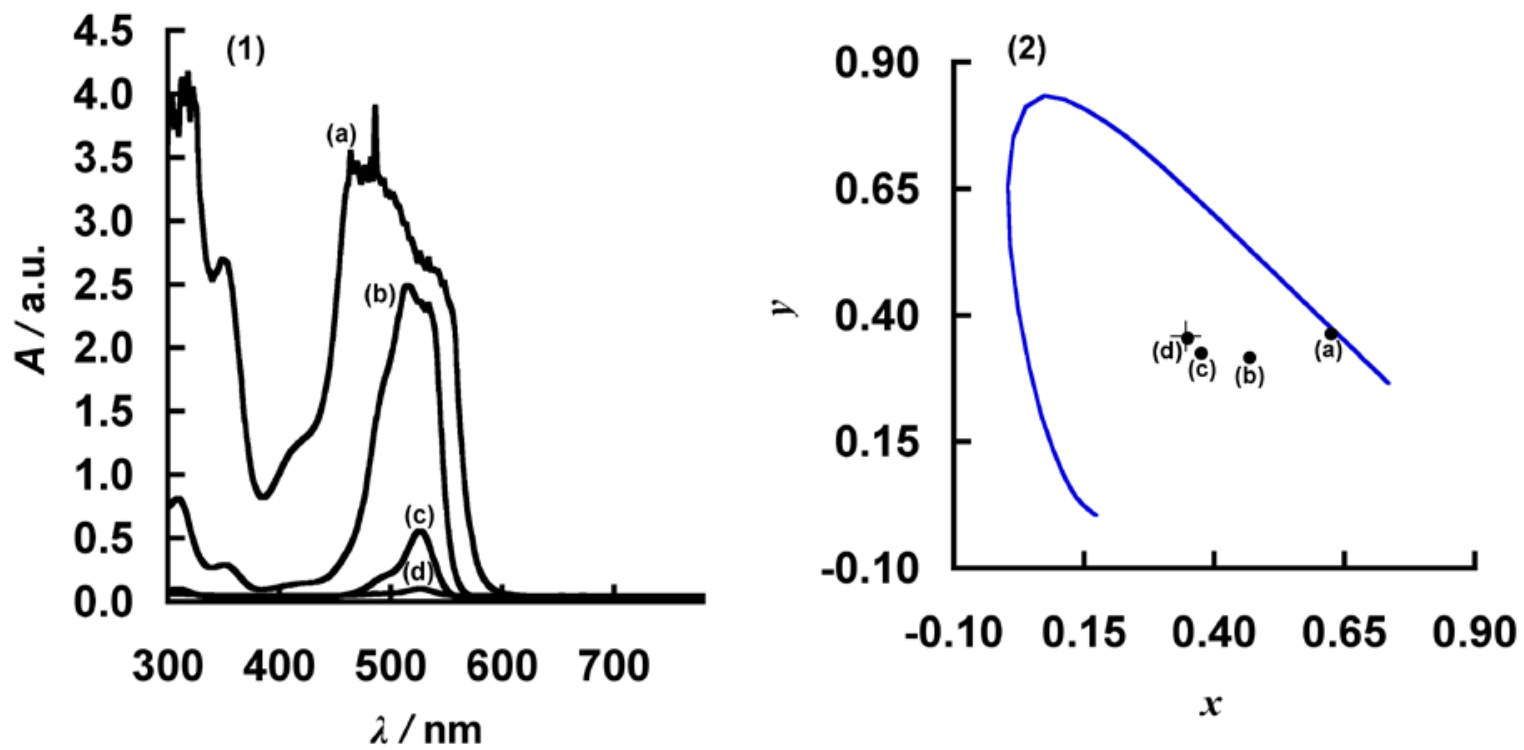
Fig. 6
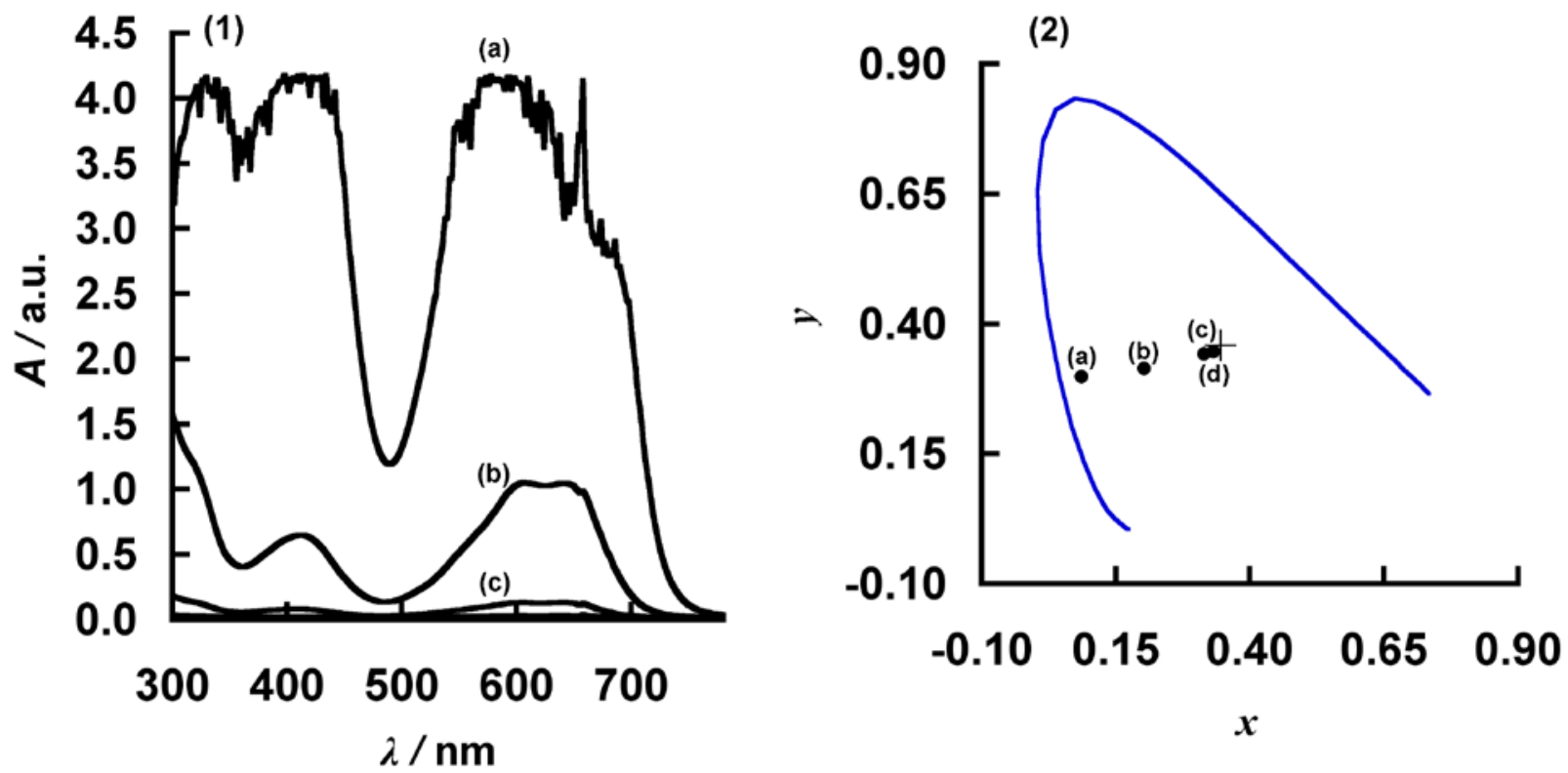
Fig. 7
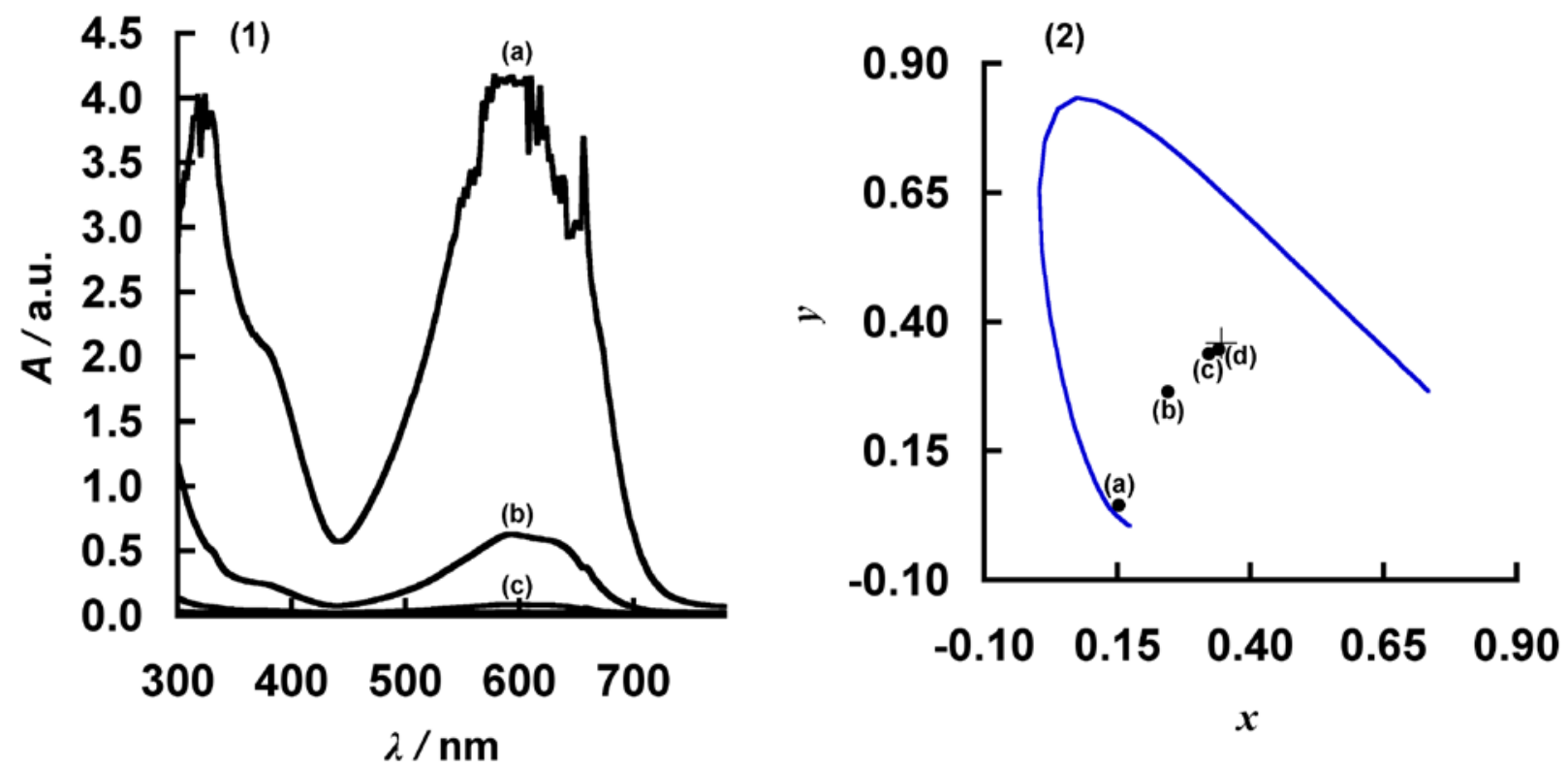
Fig. 8
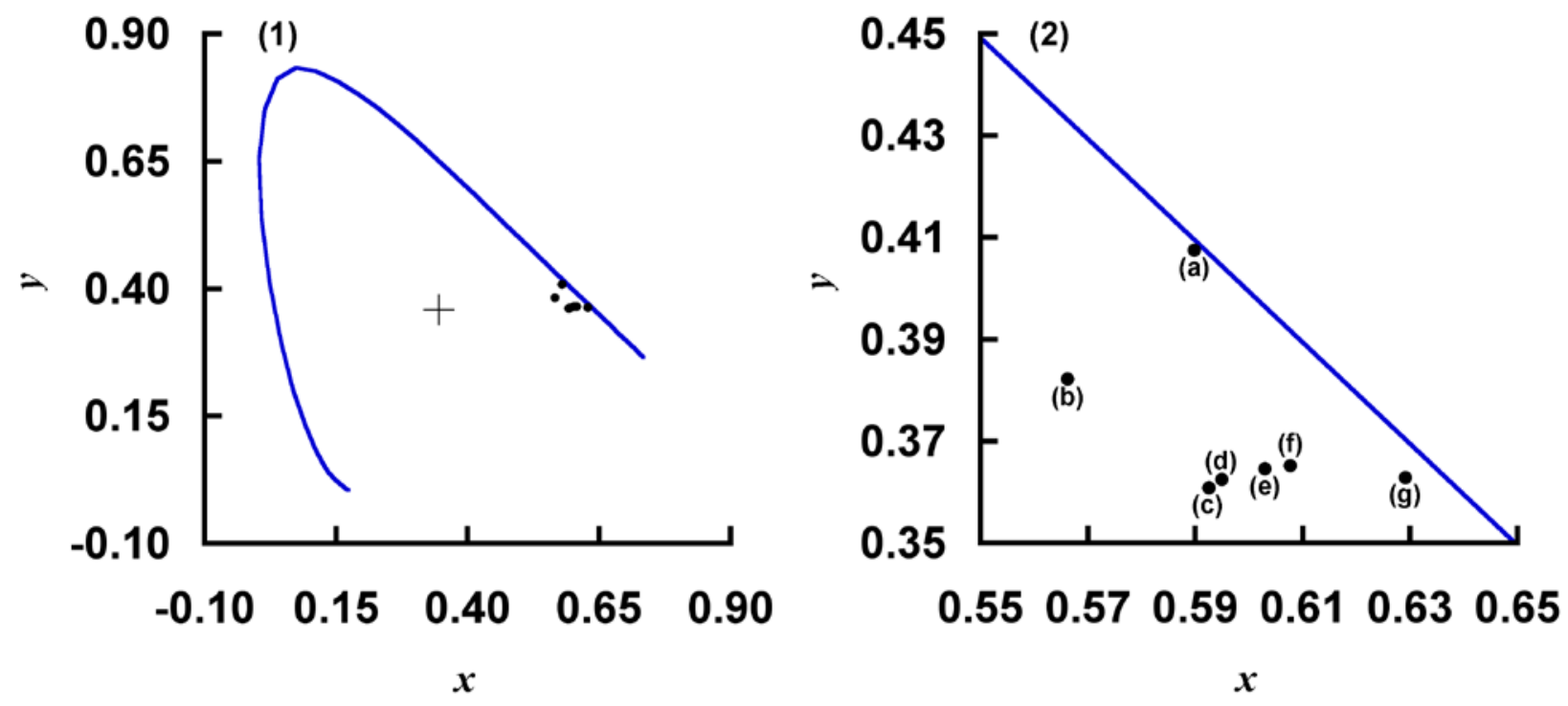
Fig. 9
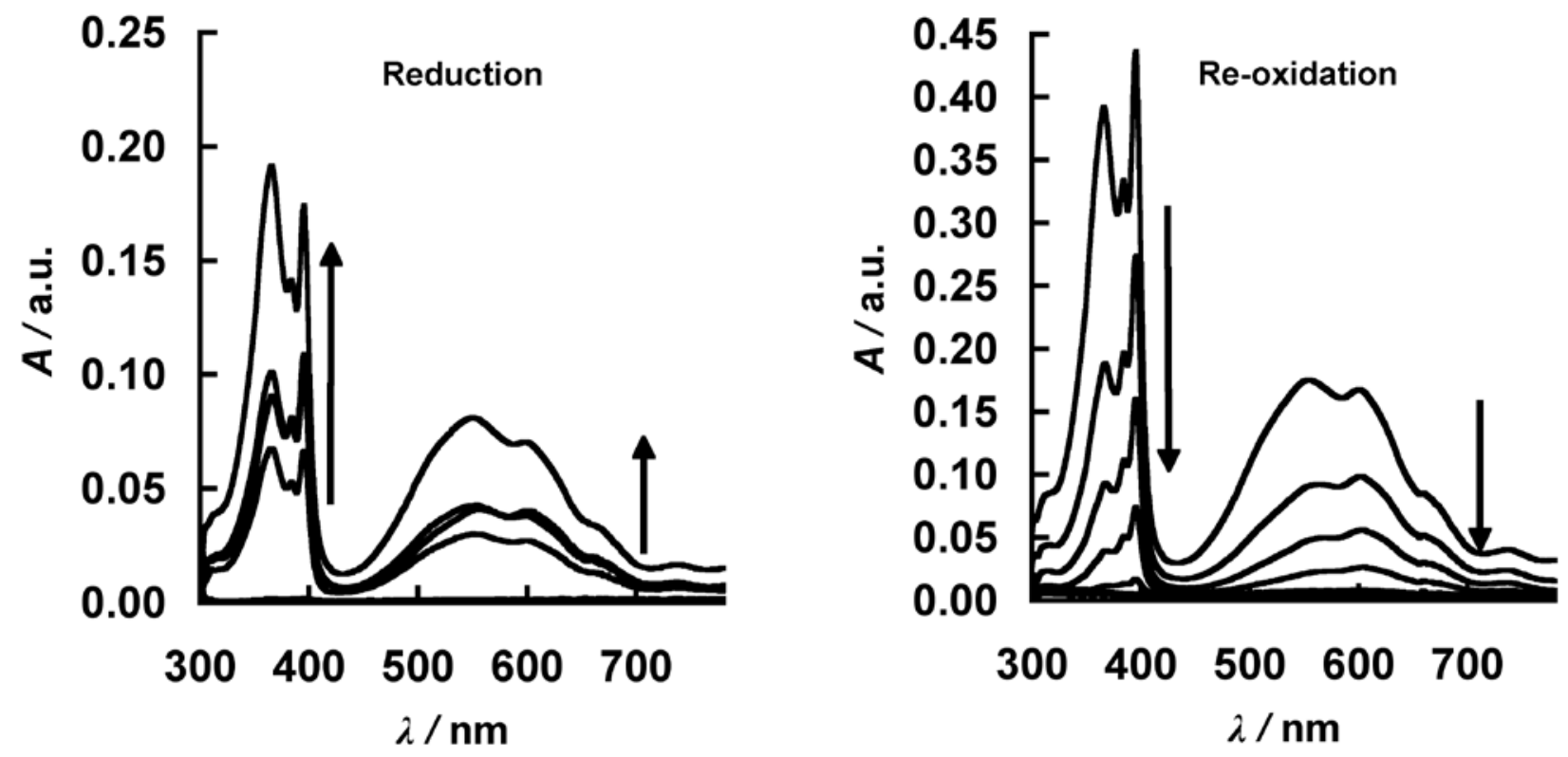
Fig. 10
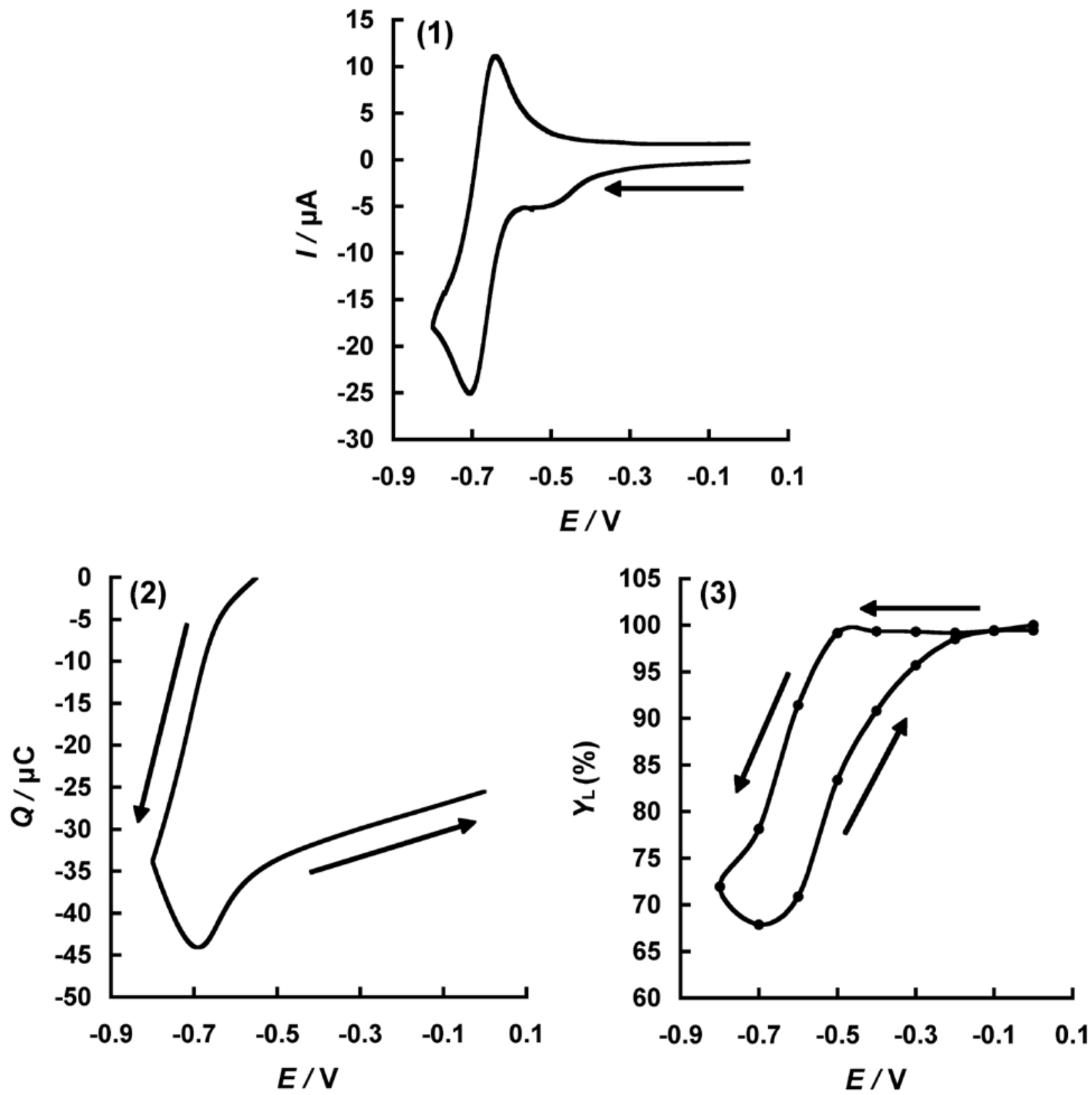
Fig. 11
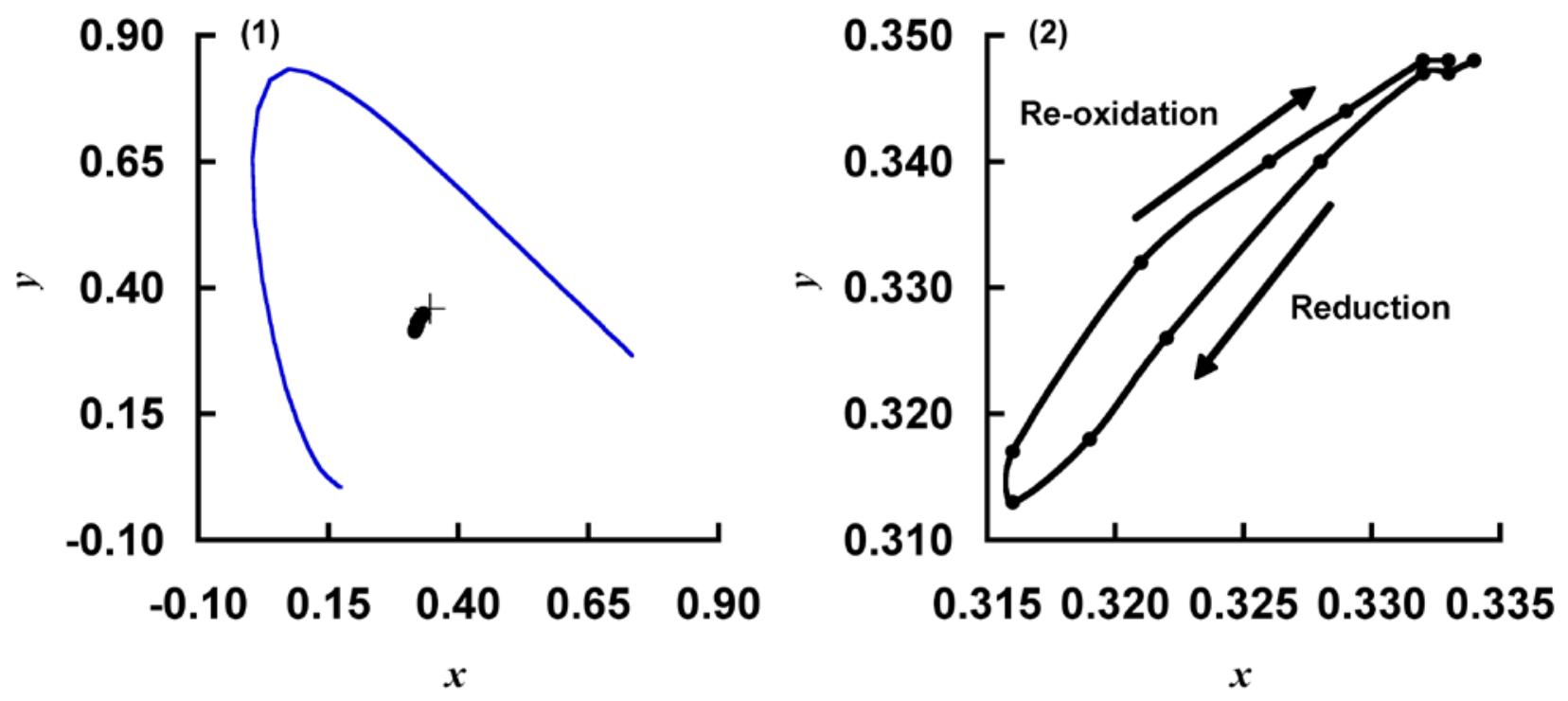
Fig. 12
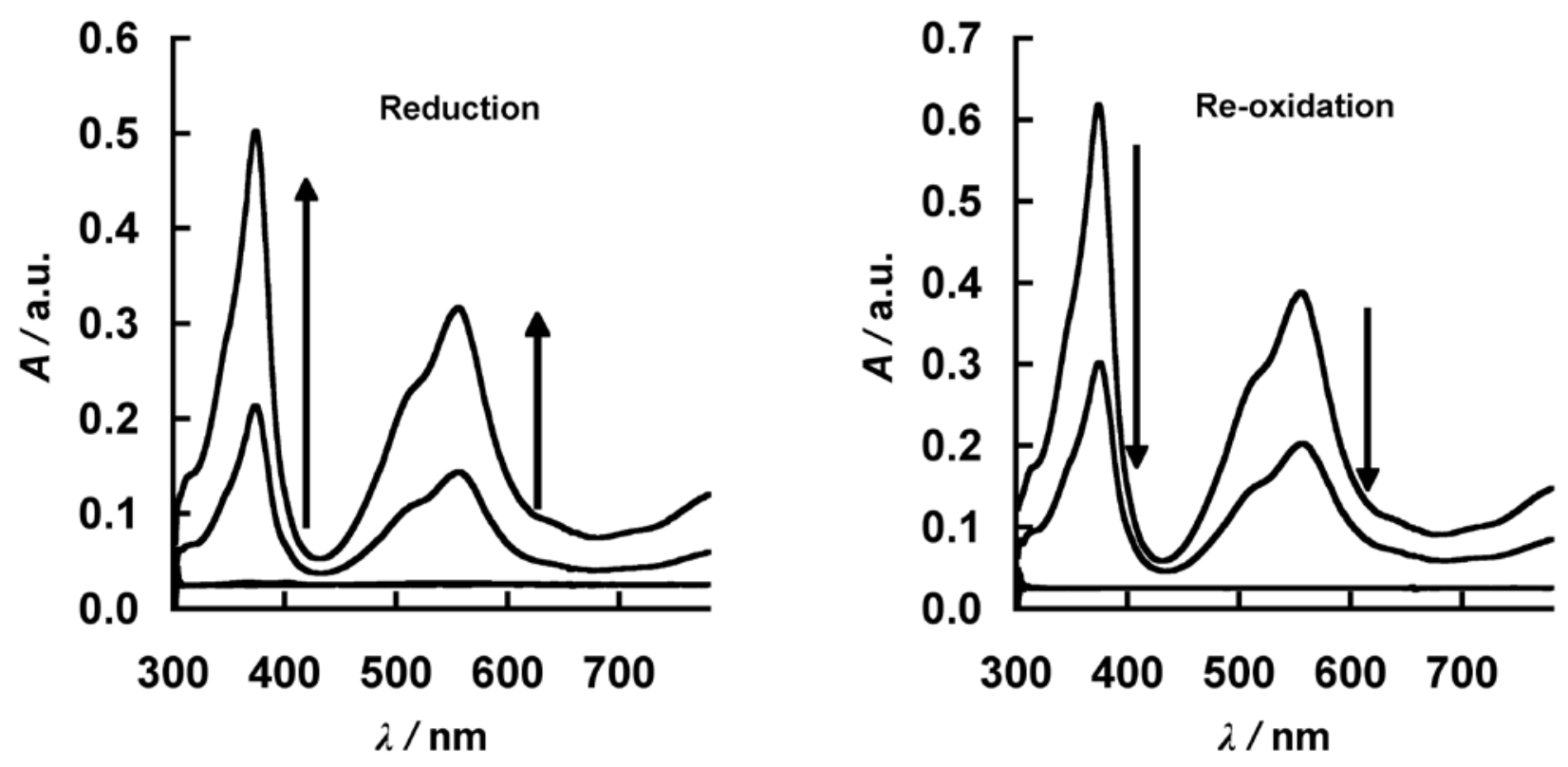
Fig. 13

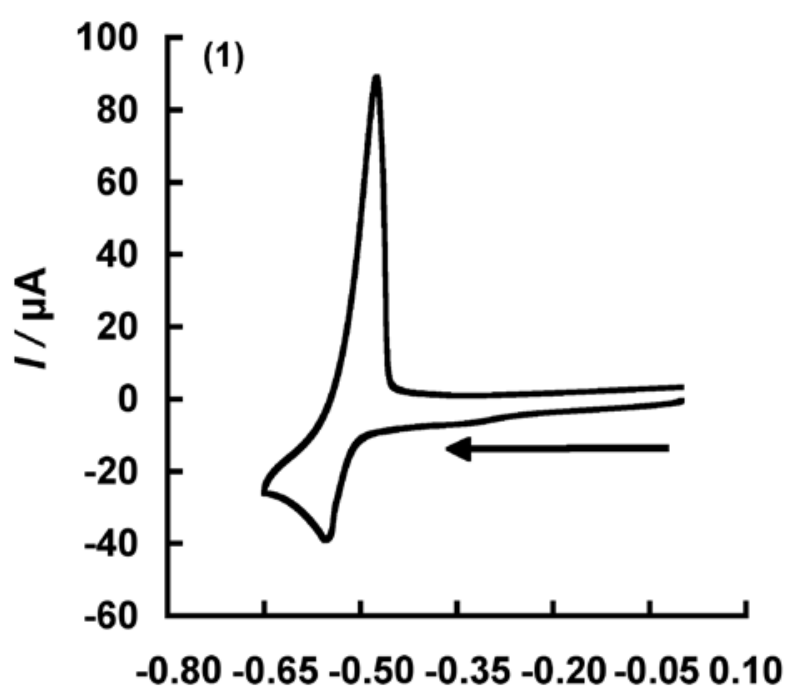

E / V

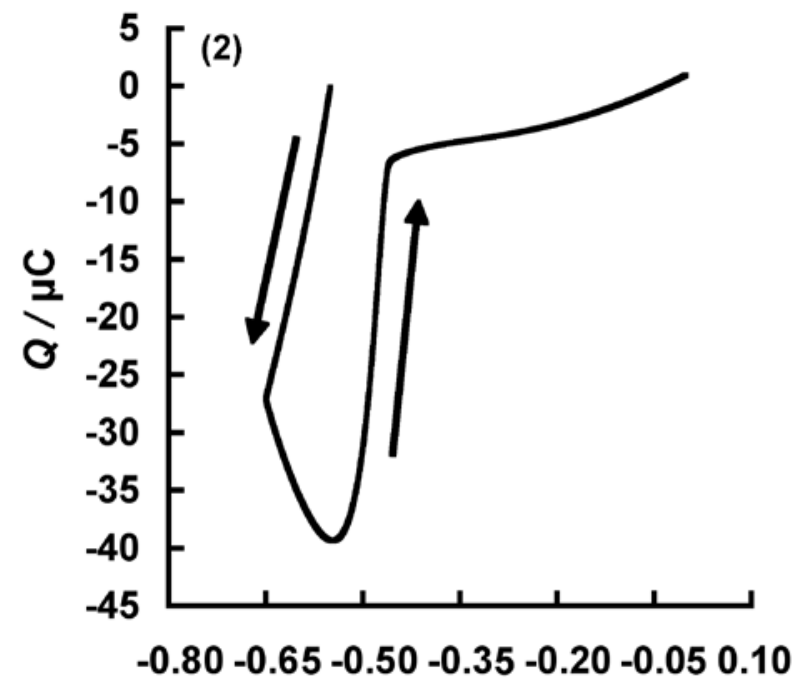

E / V

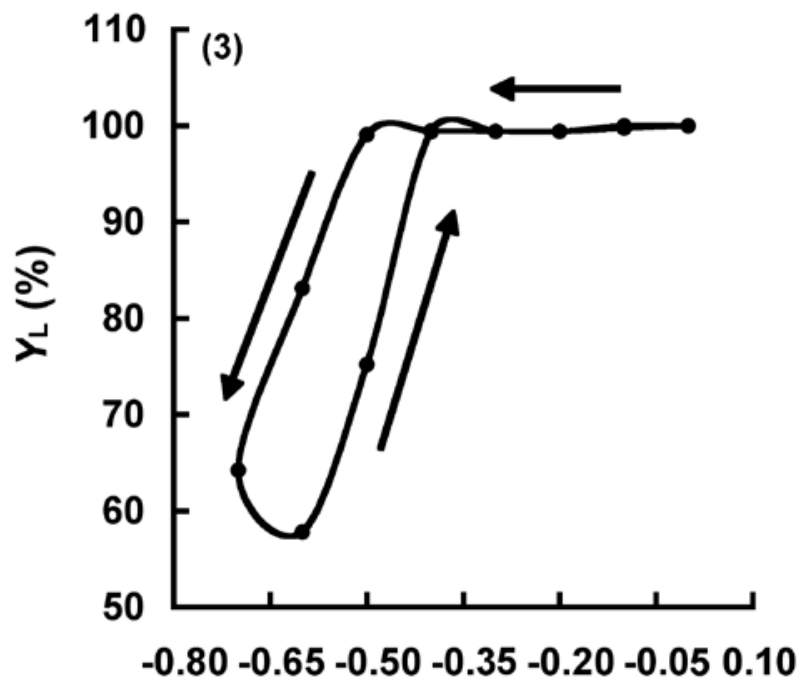

E / V 
Fig. 14
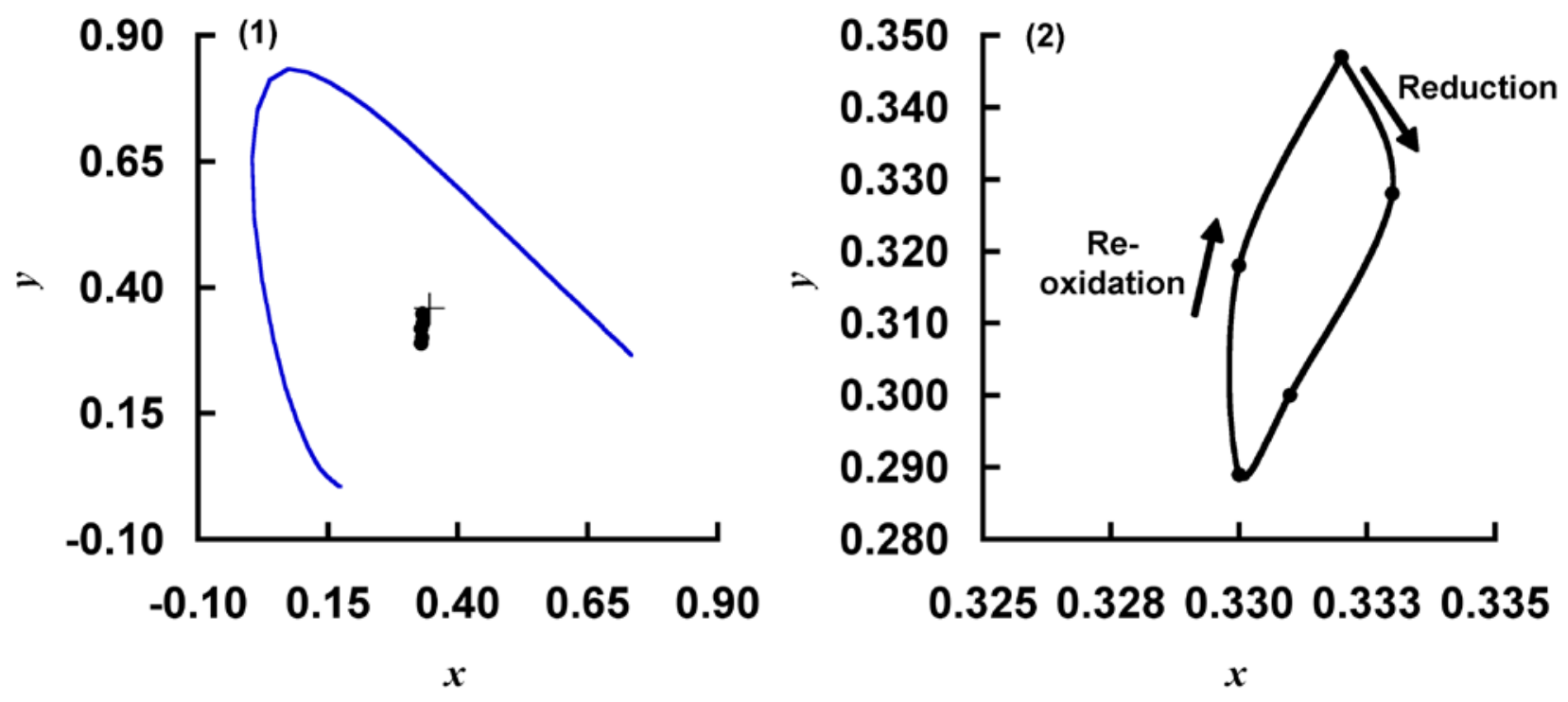
Table 1

xy chromaticity coordinates for $1 \mathrm{mmol} \mathrm{dm}^{-3}$ aqueous solutions of the red dye Erythrosin B. UVvisible region spectra were recorded in absorbance mode for 300-780 $\mathrm{nm}$. These data were then converted into chromaticity coordinates CIE 1931 using the spreadsheet.

\begin{tabular}{c|c|c} 
Sample No. & $\boldsymbol{x}$ & $\boldsymbol{y}$ \\
\hline 1 & 0.607 & 0.365 \\
2 & 0.608 & 0.365 \\
3 & 0.608 & 0.365 \\
4 & 0.608 & 0.365 \\
5 & 0.608 & 0.365
\end{tabular}


Table 2

xy chromaticity coordinates for $1 \mathrm{mmol} \mathrm{dm}{ }^{-3}$ solutions of Acid Green 25. UV-visible spectra were recorded in absorbance mode for 300-780 nm. These data were then converted into CIE 1931 chromaticity coordinates using the spreadsheet.

\begin{tabular}{c|c|c} 
Sample No. & $\boldsymbol{x}$ & $\boldsymbol{y}$ \\
\hline 1 & 0.086 & 0.298 \\
2 & 0.086 & 0.298 \\
3 & 0.086 & 0.298 \\
5 & 0.085 & 0.298 \\
5 & 0.086 & 0.298
\end{tabular}


Table 3

xy chromaticity coordinates for $1 \mathrm{mmol} \mathrm{dm}{ }^{-3}$ solutions of Remazol Brilliant Blue R. UV-visible region spectra were recorded in absorbance mode for 300-780 nm. This data were then converted into CIE 1931 chromaticity coordinates using the spreadsheet.

\begin{tabular}{c|c|c} 
Sample No. & $\boldsymbol{x}$ & $\boldsymbol{y}$ \\
\hline 1 & 0.153 & 0.045 \\
2 & 0.153 & 0.045 \\
3 & 0.153 & 0.045 \\
4 & 0.153 & 0.045 \\
5 & 0.153 & 0.045
\end{tabular}


Table 4

Numerical chromaticity coordinates for the electrochemical reduction and re-oxidation of 2 mmol $\mathrm{dm}^{-3}$ methyl viologen dication, at an ITO-glass working electrode, in an aqueous solution containing $1.0 \mathrm{~mol} \mathrm{dm}^{-3}$ potassium chloride. Data were obtained using the spreadsheet developed in the present work using calculated using the spectral power distribution of a $\mathrm{D}_{55}$ illuminant source.

\begin{tabular}{|c|c|c|c|}
\hline$E(\mathrm{~V})$ vs Ag/AgCl & $x$ & $y$ & $\% \mathbf{Y}_{L}$ \\
\hline 0.0 & 0.334 & 0.348 & 100.00 \\
\hline-0.1 & 0.333 & 0.347 & 99.45 \\
\hline-0.2 & 0.333 & 0.347 & 99.17 \\
\hline-0.3 & 0.333 & 0.347 & 99.31 \\
\hline-0.4 & 0.333 & 0.347 & 99.35 \\
\hline-0.5 & 0.332 & 0.347 & 99.14 \\
\hline-0.6 & 0.328 & 0.340 & 91.43 \\
\hline-0.7 & 0.322 & 0.326 & 78.13 \\
\hline-0.8 & 0.319 & 0.318 & 71.94 \\
\hline-0.7 & 0.316 & 0.313 & 67.87 \\
\hline-0.6 & 0.316 & 0.317 & 70.88 \\
\hline-0.5 & 0.321 & 0.332 & 83.37 \\
\hline-0.4 & 0.326 & 0.340 & 90.81 \\
\hline-0.3 & 0.329 & 0.344 & 95.70 \\
\hline-0.2 & 0.332 & 0.348 & 98.52 \\
\hline-0.1 & 0.332 & 0.348 & 99.38 \\
\hline 0.0 & 0.333 & 0.348 & 99.45 \\
\hline
\end{tabular}


Table 5

Numerical chromaticity coordinates for the electrochemical reduction and re-oxidation of 2 mmol $\mathrm{dm}^{-3} n$-heptyl viologen dication, at an ITO-glass working electrode, in an aqueous solution containing $1.0 \mathrm{~mol} \mathrm{dm}^{-3}$ potassium bromide. Data were obtained using the spreadsheet developed in the present work using calculated using the spectral power distribution of a $\mathrm{D}_{55}$ illuminant source.

\begin{tabular}{|c|c|c|c|}
\hline E (V) vs Ag/AgCl & $x$ & $y$ & $\% Y_{L}$ \\
\hline 0.0 & 0.346 & 0.359 & 100.00 \\
\hline-0.1 & 0.332 & 0.347 & 99.97 \\
\hline-0.2 & 0.332 & 0.347 & 99.41 \\
\hline-0.3 & 0.332 & 0.347 & 99.41 \\
\hline-0.4 & 0.332 & 0.347 & 99.45 \\
\hline-0.5 & 0.332 & 0.347 & 99.07 \\
\hline-0.6 & 0.332 & 0.347 & 83.10 \\
\hline-0.7 & 0.333 & 0.328 & 64.21 \\
\hline-0.6 & 0.331 & 0.300 & 57.81 \\
\hline-0.5 & 0.330 & 0.289 & 75.19 \\
\hline-0.4 & 0.330 & 0.318 & 99.35 \\
\hline-0.3 & 0.332 & 0.347 & 99.41 \\
\hline-0.2 & 0.332 & 0.347 & 99.41 \\
\hline-0.1 & 0.332 & 0.347 & 99.72 \\
\hline 0.0 & 0.332 & 0.347 & 99.97 \\
\hline
\end{tabular}

